1 Running title: Contemporary risk of extinction

\title{
4 Contemporary risk of extinction in an extreme
}

\section{5 environment}

$7 \quad$ Simone Vincenzi

8 Google scholar: https://scholar.google.com/citations?user=kiV7yTQAAAAJ\&hl=en

9 ORCID ID: https://orcid.org/0000-0002-8436-8608

10 Email: simon.vincenz@gmail.com 


\section{$11 \quad$ Abstract}

12 The increased frequency and intensity of extreme events are recognized among the

13 most worrisome aspects of climate change. However, despite increased attention from

14 scientists and conservationists, developing and testing general theories and hypotheses on

15 the effects of extreme events on natural populations remains intrinsically challenging.

16 Using numerical simulations with general — but realistic for moderately fast-leaving

17 species - parameter values, I tested some of the hypotheses on risk of extinction and

18 population and genetic dynamics in an environment in which both climate (e.g.,

19 temperature, rainfall) and point (e.g., fires, floods) extremes occur. In the simulations, a

20 quantitative trait is selected for by a climate variable, but point extremes cause trait-

21 independent massive mortalities.

22 I found additive effects between age at first reproduction and fecundity on risk of

23 extinction. The extent of population bottlenecks (operationally, the number of years in

24 which a population was at low numbers) was a good predictor of allelic richness for the

25 quantitative trait selected for by the climate. Simple models including basic demographic

26 and vital rates information of the species, along with climate/environmental measures,

27 provided excellent predictions of contemporary risk of population extinction. Mean and

28 minimum population size measured in a 10-year "observation window" were largely the

29 most important predictors of risk of population extinction in the following 10-year

30 "prediction window".

31 Keywords: population dynamics, prediction, adaptation, climate change, genetics 


\section{Introduction}

33 Extreme events are now recognized among the most worrisome aspects of climate

34 change (IPCC 2007, 2012, Jentsch et al. 2007, The One Earth Editorial Team 2020).

35 They may be defined in terms of extreme values of a continuous climate variable (e.g.,

36 daily or mean summer temperature, rainfall) on the basis of the available climate and

37 weather record (Gutschick and BassiriRad 2010), or in the form of a "point" (or discrete)

38 perturbation, such as a hurricane or a storm; the latter category also includes

39 environmental hazards such as fires and floods. Following Vincenzi (2014), throughout

40 this work I will use the term climate extreme for extreme values of a continuous climate

41 or environmental variable and point extremes for discrete extreme perturbations.

42 The genetic and demographic determinants of both adaptation to a more extreme

43 environment and contemporary risk of extinction are receiving increasing interest from

44 scientists and conservationists. Despite the increased research and management focus on

45 extremes, developing and testing general theories and hypotheses on the effects of

46 extreme events remains more challenging than for other aspects of climate and

47 environmental change (van de Pol et al. 2017). Those challenges are likely to be intrinsic

48 and unavoidable.

49 First, since the effects of extreme events are largely context-specific, developing an

50 overarching causal and predictive framework might be overly ambitious (Bailey and van

51 de Pol 2016). For instance, the emergence of adaptations may depend on both the life

52 histories of the species and the recurrence interval, intensity, and nature of extreme

53 events. Besides, the demographic and genetic effects of climate and point extremes (e.g.,

54 population crashes, loss of genetic diversity, inbreeding and maladaptation, changes in 
55 population age and size structure, disruption in the expression of quantitative traits)

56 (Bryant and Meffert 1995, Kirkpatrick and Jarne 2000) are often the result of chance and

57 are thus not easily predictable or generalizable across species or habitats. Second, climate

58 and point extremes that result in strong demographic and genetic responses are often rare

59 events, whose occurrence may be also difficult to predict. When available,

60 pre-disturbance empirical data is likely to have been collected by chance, and the studies

61 on the effects of extreme events prone to be mostly opportunistic and anecdotal instead of

62 planned and comprehensive.

63 Despite the intrinsic difficulties of developing and testing general theories on the

64 effects of climate and point extremes on natural populations, there are a few theory-based

65 predictions on the demographic and genetic consequences of extreme events that may be

66 quite general across species and habitats, although with varying degrees of modeling and

67 empirical validation.

68 The first prediction is that by reducing population size, extreme events directly

69 increase the risk of extinction of the affected populations (Willi et al. 2006, Frankham et

70 al. 2014); mathematical modeling, empirical observations, and common sense all suggest

71 that smaller populations are more likely to go extinct than larger populations. After the

72 occurrence of extreme events, in some cases the extinction of the focal population is

73 inevitable for numerical reasons (no individuals capable of reproducing survived) unless

74 there is immigration from neighboring - either unaffected or less affected - populations

75 (i.e., “demographic rescue”, Brown and Kodric-Brown 1977, Carlson et al. 2014).

76 Second, when the change in the environment is sudden, but not causing mass

77 mortalities, the evolution of fitness-determining traits might occur fast enough to stop 
78 population decline and allow population recovery before extinction (“evolutionary

79 rescue", Bell and Gonzalez 2009). However, population bottlenecks such as those caused

80 by extreme events, especially when repeated over time, are predicted to decrease additive

81 genetic variance and allelic diversity in the affected populations (Bouzat 2010). As

82 adaptive potential tends to increase with genetic variability and genetic drift may

83 overwhelm selection in small populations, the effects of extreme events on genetic

84 variability are predicted to increase both the short- and long-term risks of population

85 extinction, with smaller chances of evolutionary rescue (Falconer and Mackay 1996,

86 Willi and Hoffmann 2009).

87 Third, species may exhibit various adaptations to extreme events, some more

88 predictable and general than others. For instance, extreme, but predictable variations in

89 the flow regime of streams can select for fish life histories, such as spawning and

90 emergence time, that are synchronized either to avoid or exploit the direct (e.g., stronger

91 or weaker currents) and indirect (e.g., changes in food webs) effects of extreme flows

92 (Lytle and Poff 2004). On the contrary, unpredictable flow events such as flash floods

93 may have low direct selective consequences for the affected populations, even though

94 they might induce massive mortalities (Lytle 2000). In these cases, natural selection after

95 the extreme event is predicted to favor individuals with a high capacity for increase in

96 population size ( $r$ selection, Reznick et al. 2002). Intuitively, when after an extreme event

97 the population is reduced to a few individuals, faster reproduction may be more critically

98 needed than high fecundity, since the latter depends on being able to reproduce.

99 However, the interaction effects between age at first reproduction and fecundity on risk

100 of extinction in an extreme environment have been rarely investigated. 
101 In this work, I test using a simulation approach some of the hypotheses on risk of

102 extinction and population and genetic dynamics in an environment in which both climate

103 and point extremes occur. In previous work, Vincenzi (2014) found that the survival

104 chances of a population were found to decrease with increasing strength of selection, as

105 well as with increasing climate trend (e.g., increasing or decreasing $n$-year moving

106 average temperature, rainfall) and variability. They also found that the interactions

107 among climate trend (e.g., increase over years of average summer temperatures), climate

108 variability and probability of point extremes (e.g., fires) had negligible effects on risk of

109 extinction, time to extinction, and distribution of a quantitative trait selected for by

110 climate after accounting for their independent effects.

111 The present work focuses more on prediction than inference; prediction of future

112 observables has long been included as an aspect of biological and ecological studies, but

113 as a methodological approach it has been much less prominent than either description or

114 statistical and causal inference. The work is also not purely theoretical in scope, but is

115 motivated (and model parameter values inspired) by the study of the population and

116 genetic dynamics, and risk of extinction of marble trout Salmo marmoratus living in

117 Slovenian streams (Vincenzi et al. 2016). Marble trout populations are affected by flash

118 floods in autumn and droughts in summer, and the climate threat to the persistence of

119 marble trout is likely to worsen with climate change; for instance, the increase in intra-

120 annual variability in rainfall is predicted to increase the frequency of flash floods (Janža

121 2013). However, since there is a need for more general investigations of risk of

122 population extinction and population and genetic dynamics in presence of climate and 
123 point extremes, I developed a more widely applicable modeling and conceptual

124 framework.

125 I modeled an idealized situation of additive genes, a closed population of moderate

126 size with random mating, and variable across simulations — but fixed within

127 simulations - age at first reproduction and expected number of offspring per mating pair,

128 climate trend and variability (i.e., the parameters of the distribution of climate variable

129 that is selecting for a quantitative trait), selection strength, and frequency and severity of

130 point extremes. I assume that point extremes cause massive mortalities, but no trait other

131 than good fortune increases the survival chances of an individual when point extremes

132 occur.

133 First, I tested whether in an extreme environment the extent of population bottlenecks,

134 which I operationally defined as the total number of years with "depressed" population

135 size (e.g., $\sim 1 / 3$ to $\sim 1 / 10$ of the habitat carrying capacity), could help predict allelic

136 richness at the end of simulation time for the quantitative trait selected for by the climate

137 variable. Second, I tested whether quantitative trait adaptation was correlated with the

138 increased frequency of theoretically advantageous alleles (i.e., their allelic values are in

139 the same direction of the change in the environment) and whether the genetic dynamics

140 of the populations could be predicted using information on the climate and on the

141 population life histories. Third, I tested for interaction effects between age at

142 reproduction and fecundity on risk of population extinction. Finally, I tested whether it is

143 possible to predict the extinction or survival of a population in a 10-year "prediction

144 window" (i.e., contemporary extinction) when measuring or observing some of the

145 environmental characteristics of the habitat (e.g., occurrence of extreme events) and of 
146 the population (e.g., population size, age at reproduction) during a 10-year "observation

147 window" that immediately precedes the "prediction window".

\section{Material and methods}

149 The model I use in this work is an extension of the model developed in Vincenzi

150 (2014). The choice of parameter values for the present work was informed by the

151 available literature on extreme events, population monitoring, and species life histories,

152 and by the results of Vincenzi (2014).

\subsection{Overview of the model}

154 I consider a population of monoecious individuals living in a habitat whose population

155 ceiling is $K$ (Mangel and Tier 1993). The population is geographically isolated, with

156 neither immigration nor emigration from or to other populations. A single quantitative

157 trait $a$ corresponding to its breeding value for a phenotypic trait $z$ characterizes the

158 individuals. The population has discrete overlapping generations with $N(t)$ total

159 individuals, where $t$ is time in years. The environment is described by an optimum

160 phenotype $\Theta(t)$ that changes over time as a result from variations in a climate driver such

161 as rainfall or average summer temperature, which selects for the trait $z$. The distance

162 between the optimum phenotype $\Theta(t)$ and the trait $z_{\mathrm{i}},\left(\Theta(t)-z_{\mathrm{i}}\right)$ of the individual $i$ defines

163 the maladaptation of the individual $i$ with respect to the optimum phenotype (or,

164 alternatively, it defines the "extremeness" of the climate event for the individual). Point

165 extreme events such as floods or fires cause non-selective high mortality in the

166 population, i.e. every phenotype has the same chances of surviving the event. 


\subsection{Optimum phenotype}

168 The expected optimum phenotype $\mu_{\Theta}(t)$ moves at a constant rate $\beta_{\mu, \Theta}$ over time (i.e.,

169 trend), fluctuating randomly around its expected value $\mu_{\Theta}(t)$. The optimum phenotype

$170 \Theta(t)$ is randomly drawn at each time step $t$ from a normal distribution $\Theta(t) \sim N$

$171\left(\mu_{\Theta}(t), \sigma_{\Theta}(t)\right)$. It is equivalent to consider $\Theta(t)$ as both the optimum phenotype and the

172 value of a continuous climate variable (e.g., mean summer temperature or yearly rainfall),

173 and I will use the two terms interchangeably throughout this work.

174 Mean and variance of the climate variable at time $t$ are thus:

$$
\begin{cases}\mu_{\theta}(t)=\mu_{\theta, 0} & \text { when } t<t_{c h} \\ \mu_{\theta}(t)=\mu_{\theta, 0}+\beta_{\mu, \theta}\left(t-t_{c h}\right) & \text { when } t \geq t_{c h}\end{cases}
$$

$$
\text { where } t_{\mathrm{ch}} \text { is the time at which there is a change }(c h) \text { in the climate. Eq. (1) }
$$

184 indicates that the directional climate trend steadily increases through time after $t_{\mathrm{ch}}$ years

185 and that the increase in variability starts after $t_{\text {ch }}$ years, but stops after $t_{\mathrm{ch}}+t_{\text {inc }}$ years. An

186 alternative formulation to Eq. (1) would allow variability to more slowly build up over

187 time; however, in the case of variability slowly increasing over longer times, the effects

188 of higher climate variability would affect the individuals only towards the end of

189 simulation time. As informed by the goals of this work, I preferred to let individuals 
190 trying to survive a higher climate variability (which is among the least investigated

191 aspects of climate and environmental change) for a longer time period.

192 With the model formulation of Eq. (1), both the mean and variance of the distribution

193 of the climate variable change over time so as to make the occurrence of events more

194 likely after climate change (i.e., $t>t_{\mathrm{ch}}$ ) than before, since after climate change, the

195 realized (i.e., random draw from the statistical distribution of climate) climate is

196 increasingly likely to be in the region of extremes (say, in the right $5 \%$ or $2.5 \%$ of the

197 Gaussian distribution of climate) of the statistical distribution of climate before climate

198 change.

199 Point extreme events $E$ leading to trait-independent high mortalities occur with annual

200 probability $\mathrm{p}\left(E_{\mathrm{b}}\right)$ when $t<t_{\text {ch }}$ (i.e. b - before climate change) and $\mathrm{p}\left(E_{\mathrm{a}}\right)$ when $t>t_{\mathrm{ch}}$.

\subsection{Quantitative trait and survival}

202 I model the phenotype $z$ of an individual $i, z_{\mathrm{i}}$, as the sum of its genotypic value $a_{\mathrm{i}}$ and a

203 statistically-independent random environmental effect $e_{\mathrm{i}}$ drawn from $N\left(\mu_{\mathrm{E}}, \sigma_{E}^{2}\right)$ :

$$
z_{\mathrm{i}}=a_{\mathrm{i}}+e_{\mathrm{i}}
$$

205 The narrow sense heritability $h^{2}=\sigma_{G}^{2} / \sigma_{z}^{2}$ is the proportion of the phenotypic variance

$206 \sigma_{z}^{2}$ present in the population that is explained by the additive genetic variance $\sigma_{G}^{2}$ (i.e.

207 the variance of $\boldsymbol{a}$ in the population).

208 For an individual $i$, the genetic value $a_{\mathrm{i}}$ is determined by $n_{1}$ freely recombining diploid

209 loci, with additive allelic effects within- and among-loci, that is $a_{i}=\sum_{j=1}^{l} n_{i, j}$, where $n_{i, j}$

210 is the sum of the allelic values at locus $j$. For computational reasons, I chose $n_{1}=10$.

211 Allelic values are randomly drawn from a Gaussian distribution with mean of 0 and 
212 variance equal to $\sigma_{\mathrm{a}}^{2}$. For simplicity, I did not model either dominance or epistatic

213 variation or other complicating factors such as genotype-environment interaction and

214 linkages. Likewise, I did not model mutation, since previous work has shown that

215 mutation does not appear to have any effect short-term on extinction risk and the

216 evolution of traits on contemporary temporal scales (Vincenzi 2014).

217 Stabilizing selection is modeled with a Gaussian function (Bürger and Lynch 1995,

218 Zhang 2012), with fitness $W$ (Endler 1986) for an individual with phenotypic trait $z_{\text {i }}$ equal

219 to:

$$
W\left(t, z_{i}\right)=W(t)_{i}=\exp \left[-\frac{\left(z_{i}-\Theta(t)\right)^{2}}{2 \omega^{2}}\right]
$$

221 and equivalent in this model to the annual survival probability of individual $i$. The

222 curvature of the fitness function near its optimum increases with decreasing $\omega^{2}$; it follows

223 that that the smaller $\omega^{2}$, the stronger is selection. Stabilizing selection is usually measured

224 by the standardized quadratic selection gradient $\gamma$, which is defined as the regression of

225 fitness $W$ on the squared deviation of trait value from the mean (Lynch and Walsh 1998).

226 An optimum phenotype in the tails of the distribution is likely to cause a large drop in

227 population size and can be considered an extreme climate event (Fig. 1).

228 The median $\gamma=-0.1$ for stabilizing selection found by Kingsolver et al. (2001)

229 corresponds to a value of $\omega^{2} / \sigma_{E}^{2}=5 /\left[1-h^{2}\right]$, where $\sigma_{E}^{2}$ is the variance of the

230 environmental component of the phenotype defined in Eq. (2), when stabilizing selection

231 is modeled using a Gaussian fitness function.

232 Eq. (3) can be written: 


$$
W_{i}=\exp \left[-s \cdot\left(z_{i}-\Theta(t)\right)^{2}\right]
$$

235 about 0.08 .

236 I assumed that both strength of selection $s$ and environmental variance $\sigma_{E}^{2}$ remain

237 constant through time. When a point extreme occurs, the probability of yearly survival of

238 individuals $i$ is $W_{i}\left(1-m_{E_{I}}\right)$, where $m_{E_{I}}$ is mortality caused by the point extreme event.

\subsection{Simulations}

240 As this study focuses on the more immediate effects of climate change, the

241 simulations last 250 years. Parents mate at time $t$-1, offspring are born at time $t$ and

242 become of age 1 at $t+1$. The sequence of operations is mortality of adults, mating and

243 reproduction, mutation, mortality of offspring. At the start of each simulation, for each

244 individual a value of $a$ and $e$ (Eq. 2) is randomly drawn from their initial distribution. A

245 population is considered extinct if at any time during the simulation there are fewer than

2462 individuals in the population. Parents form mating pairs starting at age $a_{\mathrm{f}}$ and produce a

247 number of offspring randomly drawn from a Poisson distribution with intensity $\lambda_{\mathrm{o}}$.

248 Offspring receive for the same locus one allele from each parent.

\subsubsection{Parameter values}

250 With numerical simulations, it is inevitable to face a trade-off between specificity and

251 generalizability of the modeled processes and of the simulation results. I reduced

252 parameter space by fixing $K=500$ individuals, $\mu_{\Theta, 1}=0, \sigma_{\Theta, 1}=1, \mu_{E}=0, \sigma_{E}^{2}=1, \sigma_{G}^{2}=2$

$25310^{-1}, \sigma_{\mathrm{a}}=510^{-2}, \mathrm{p}\left(E_{\mathrm{I}, \mathrm{b}}\right)=0.05$, and $t_{i n c}=25$. For the other parameters, I chose range of 
254 values that are both realistic for natural populations with moderately fast life histories,

255 like salmonids (e.g., age distribution skewed toward individuals younger than 10 years

256 old, sexual maturity reached when individuals are between 1 and 4 years old), and

257 instrumental for the main goal of the study, e.g., testing hypotheses on the effects of

258 extreme events on population and genetic dynamics and on risk of extinction.

259 I performed simulations with selection strength $s$ equal to either $810^{-2}$ (average

260 selection strength) or $1.110^{-2}$ (moderately strong selection). For the rate of increase in the

261 mean of the climate variable, I used $\beta_{\mu, \Theta}=0$ (base scenario) and $1.510^{-2}$. I used rates of

262 the increase in the standard deviation of the climate variable $\beta_{\sigma, \Theta}$ from 0 (base scenario)

263 to $1.510^{-2}$. According to Bürger and Lynch (1995), when the standard deviation of the

264 distribution of the optimum $\sigma_{\theta}$ reaches the same order of magnitude as the width $\omega$ of the

265 fitness function, the population is at risk of going suddenly extinct, with little role played

266 by genetics. Therefore, I chose values of $\beta_{\sigma, \Theta}$ that strongly increase the probability of

267 climate extremes, but did not inevitably make the population go extinct.

268 I used frequency of point extreme events $\mathrm{p}\left(E_{\mathrm{a}}\right)$ of either $510^{-2}$ (no variation before and

269 after climate change, corresponding to a recurrence interval of 20 years), $1010^{-2}$ (i.e.,

270 recurrence interval is 10 years) or $1510^{-2}$ (Table 1). I used moderate mortalities caused

271 by point extremes (simulations with $m_{E}$ equal to either $\left.0.3,0.5,0.7\right)$ and moderate $\mathrm{p}\left(E_{\mathrm{a}}\right)$,

272 since with higher mortality induced by point extremes and higher probability of their

273 occurrence the system will be largely driven by the point extremes, with no or little role

274 of genetics and demography in determining population dynamics and risk of extinction. 
275 For the Poisson distribution of the yearly number of offspring per mating pair, I used

$276 \lambda_{\mathrm{o}}$ equal to either $1.0,1.5,2.0$ or 2.5 and age at first reproduction from 1 to 4 years old

277 with a step of 1 . Parameter values are reported in Table 1.

\subsubsection{Initialization}

279 To reach mutation-selection-drift balance, I first let the population evolve for $t_{\text {ch }}$ years

280 in an environment in which mean and variance of the distribution of the optimal

281 phenotype $\Theta$ are constant. In preliminary simulations it was found that after $t_{\mathrm{ch}} \sim 100$

282 years both phenotypic mean and variance did not noticeably change. Then, the mean of

$283 \Theta$ increases for 150 years and the variance of $\Theta$ for 25 years, which was then kept

284 constant up to the end of simulation time.

285 I started every simulation replicate with 500 individuals. I modeled 10 alleles present

286 in the population for each locus, which value was randomly drawn from a normal

287 distribution $N\left(0, \sigma_{A}^{2}\right)$. Since I set $\sigma_{E}^{2}=1$ and $\sigma_{G}^{2}=0.2$, the narrow sense heritability $h^{2}$

288 was around 0.2 at $t=1$, close to what commonly observed for life-history traits (Lynch

289 and Walsh 1998) and consistent with the Gaussian allelic approximation including only

290 quasi-neutral and adaptive mutations, for which $\sigma_{G}^{2}=0.225 \sigma_{E}^{2}$ (Lande 1995).

\subsubsection{Characterization of simulations}

292 At the single-replicate level, to characterize the behavior of the simulated populations

293 I tracked or recorded (among other results): (a) whether the population was extinct or still

294 persisting at the end of the simulation time ( 0 for persistence and 1 for extinction, in the

295 latter case I also recorded the year of extinction). At each time $t$, I then recorded: $(b)$ the

296 distribution of the trait $z$ in the population and individual maladaptation; (c) population 
297 size $N$ after mortality of adults; $(d)$ total number of alleles and allelic frequencies (the

298 latter every 25 years).

299 For an ensemble of realizations (10 replicates for a fixed set of parameters) I also

300 computed the frequency of population extinction as the number of replicates in which the

301 population went below two individuals during simulation time.

\subsection{Statistical analysis}

303 I used simulation results as pseudo-empirical data and analyzed them with standard

304 statistical and machine learning models. The main focus of the statistical analyses and

305 modeling was more on prediction than on inference or traditional $p$-value

306 hypothesis-testing.

307 I estimated parameters of Generalized Additive Models (GAMs, Wood 2006),

308 Generalized Linear Models (or Ordinary Least-Square regression models, McCullagh and

309 Nelder 1989), and Random Forests (Breiman 2001a) using as response variable either $(i)$

310 the total number of alleles (overall allelic richness) at the end of simulation time for the

311 populations that persisted, (ii) the difference in mean allelic frequency of the top $10 \%$ and

312 bottom 10\% (according to their allelic value, top 10\% were the alleles with the bigger

313 allelic value and vice versa for the bottom 10\%) of alleles. For (i), in particular, I tested

314 whether the number of consecutive years ( $n$ low, the only variable in the GAM models

315 for which I hypothesized a non-linear effect on the total number of alleles) under a low

316 population size threshold ( $\operatorname{tr}$ _low) contributed to predicting the number of alleles at the

317 end of simulation time, in addition to climate variables and vital rates such as expected

318 intensity and frequency of extreme events, the variance of the optimum, expected yearly

319 number of offspring per mating pair and age at first reproduction. I calculated tr_low 
320 using either 150, 100, or 50 individuals as the threshold (results were consistent when

321 using either 150,100 , or 50 individuals). For (ii), when the climate is changing (i.e., $\beta_{\mu, \Theta}$

$322>0$ ), alleles with positive allelic values are expected to be more adaptive than those with

323 negative (or positive, but smaller) allelic values. I tested whether a model including

324 climate variables and vital rates trained on data from $80 \%$ of the replicates that did not go

325 extinct could predict the difference in mean allelic frequency at year 250 (end of

326 simulation time) of the top and bottom $10 \%$ of alleles according to their allelic values in

327 the test data set (20\% replicates that did not go extinct). I chose the top and bottom $10 \%$

328 of the alleles ( 10 alleles in the top and bottom sets), since the fate of single alleles is more

329 likely to be affected by chance than that of a group of advantageous alleles.

330 Then, I investigated whether a combination of demographic and environmental factors

331 measured or estimated in a short time window ("observation window") can predict the

332 risk of extinction of the population in the following years ("prediction window"). First, I

333 set aside a balanced test data set of simulation replicates (50\% that went extinct and $50 \%$

334 that survived) - these simulations were not used in any phase of either model

335 development or model training. Second, since the number of simulations that went extinct

336 was approximately one-third of the number of those that survived, I augmented the data

337 set by replicating 3 times the simulations that went extinct and were not included in the

338 test data set.

339 Third, I fitted GLMs and GAMs with binomial error distribution (i.e., logistic

340 regression), and classification Random Forests (RFs) with population extinction (1) or

341 persistence $(0)$ between $\left(t_{\text {ext }}-u\right)$ as response variable, where $t_{\text {ext }}$ is either (a) the time at

342 extinction for the replicate that went extinct, or (b) a random deviate from a uniform 
343 distribution bounded between 20 and 250 for the replicates that survived; $u$ is a random

344 deviate from a uniform distribution bounded between 1 and 10 years. This way, I am

345 trying to model extinction or persistence not at a specific time, but in a "prediction

346 window" of 10 years, whose beginning lays between year 10 and year 240 of simulation

347 time. I used as candidate predictors, as measured in the 10 years ("observation window")

348 before the "prediction window", minimum and mean population size $N$, the maximum

349 value of the optimum phenotype, the expected yearly number of offspring per mating

350 pair, age at first reproduction, and maximum and mean distance over the observation

351 window between the mean phenotype and the optimum (i.e., maximum and mean

352 population-level maladaptation, or maximum and mean "extremeness" of the climate).

353 In other words, I wanted to test whether a model including climate and population

354 traits measured over a limited time frame could predict the extinction or persistence of

355 the population in the years immediately following the end of the "observation window".

356 The choice of the length of both the observation and prediction windows was based on

357 what it is considered a "reasonable" length of population monitoring when the goal is to

358 detect changes in population size and estimate the risk of population extinction. White

359 (2019) collected the time series of population size of 822 populations of vertebrate

360 species and found that $72 \%$ of time series required at least 10 years of continuous

361 monitoring to achieve a high level of statistical power to detect significant trends in

362 abundance (the code associated with this work allows to use between 5 and 20 years as

363 length of the observation and prediction windows).

364 For the GAMs and GLMs, I estimated the optimal cutoff given equal weight to

365 sensitivity (the probability that the model predicts extinction when the replicate went 
366 extinct) and specificity (the probability that the model predicts persistence when the

367 replicate persisted). Then, I tested the model by predicting population extinction and

368 persistence on the test dataset using the computed optimal cutoff. For the classification

369 RF models, I directly used the binary prediction (population going extinct or surviving)

370 from the models. I used different modeling approaches because I did not explicitly model

371 any mechanism or process that can be hypothesized to lead to extinction (i.e., models are

372 correlative and not mechanistic), and different modeling approaches can give different

373 insights on how contemporary extinctions are predicted (e.g., tree-based models like RFs

374 provide a measure of variable importance for predicting the target variable (Breiman

375 2001a) and GAMs can model non-linear relationships between predictors and target

376 variable using semi-parametric estimation). For the GAMs and GLMs, I centered and

377 scaled the predictors in order to compare their importance (Schielzeth 2010). As I use

378 realistic variable ranges representing the variability that may be observed in nature, some

379 of the estimated parameters can be compared in terms of effects on a standardized scale. I

380 also fitted the same models using non-standardized predictors to test for possible data

381 leakage between training and testing data sets (results were directionally the same). I did

382 not include interactions among predictors in the models in order to improve the

383 interpretability of results. I visually checked residuals for violation of model assumptions.

\section{Results}

385 Results are fully reproducible. Data and R code are at

386 https://github.com/simonevincenzi/Contemporary_Extinction. 
After year 100, the directional trend, the increase in variability of climate, and the

388 increased occurrence and severity of point extremes led to noticeable fluctuations in

389 population size over time (Fig. 1). Twenty-one per cent of the 34560 simulation

390 replicates went extinct. As expected, risk of extinction increased with higher frequency

391 and severity of point extreme events, older age at first reproduction, and fewer offspring

392 produced per mating pair (Fig. 2). Given an expected yearly number of offspring per

393 mating pair, the proportion of replicates that went extinct increased approximately

394 linearly with age at first reproduction (Fig. 2a). When considering all replicates or only

395 the most extreme scenario, for a fixed expected number of offspring produced per mating

396 pair, increasing age at first reproduction by one year would increase the probability of

397 going extinct by approximately $10 \%$ (Fig. 2a). The combination of relative high

398 frequency and high severity of extreme events led to a noticeably higher proportion of

399 replicates that went extinct (Fig. 2b). Among the replicates that went extinct, 16\% of

400 them were not affected by a point extreme in the 10 years before extinction and $34 \%$ in

401 the 5 years preceding extinction.

402 In populations that persisted until the end of simulation time, the GLM and GAM models

403 that included $n$ low provided a good prediction of the total number of alleles at the end of

404 simulation time (Table 2). The total number of years with population size smaller than

405150 individuals had a strong, negative non-linear effect on the total number of alleles at

406 the end of simulation time (Fig. 3). Models that did not include $n \_l o w$ had much lower

407 predictive performance (Table 2).

408 Models for differences in allelic frequency of more or less theoretically advantageous

409 alleles were able to explain less than $5 \%$ of the variance of the target variable (Fig. 4). 
410 The average value of population-mean phenotype $\bar{z}$ in the last ten years of simulation

411 time was negatively correlated with the difference in frequency of top and bottom $10 \%$ of

412 alleles according to their allelic value at the end of simulation time $(r=0.71, p<0.01)$.

413 The GLM, GAM, and RF models fitted on the training data sets had similar high

414 predictive accuracy and low false positive and negative rates when predicting extinction

415 or survival in the 10-year "prediction window" (Table 3). For more than $98 \%$ of

416 replicates included in the test data set, the GLM, GAM, and RF models provided the

417 same prediction of either extinction or persistence (Fig. 5). In the GAM model, only

418 minimum population size in the observation window had a strong non-linear (negative)

419 effect on the log-odds of population extinction. Likewise, minimum population size was

420 the most important predictor in the RF model (Fig. 6a). The models without minimum

421 and mean population size as predictors had fairly low accuracy (Table 3). The RF model

422 without minimum and mean population size as predictors found age at reproduction and

423 expected yearly number of offspring per mating pair as the most important predictors of

424 contemporary extinction (Fig. 6b).

\section{Discussion}

426 Understanding and predicting the effects of extreme events on risk of extinction and

427 population and genetic dynamics of natural populations is critical for both population

428 forecasting and for managing human intervention in an increasingly more extreme world.

429 The results of the numerical simulations showed additive effects — with largely no

430 interaction effects - between age at first reproduction and fecundity on risk of extinction

431 for the range of values I simulated. In the replicates that survived up to the end of 
432 simulation time, the total number of years in which the population was at a small size was

433 a good predictor of allelic richness for the quantitative trait under selection. The

434 population frequency of theoretically advantageous alleles was strongly correlated with

435 the mean value of the phenotype under selection but was otherwise largely unpredictable.

436 Last, simple models including basic demographic and vital rates information, along with

437 climate and environmental data, provided excellent predictions of contemporary risk of

438 population extinction.

\section{$439 \quad$ 4.1 Life histories}

440 Life-history theory predicts a prevalence of fast life histories in environments in which

441 extreme events occur (Winemiller 2005). Fast life histories-usually defined as including

442 a combination of faster body growth early in life, younger age at maturity, and higher

443 reproductive effort early in the reproductive life of the individual—should allow for

444 faster population growth rate after a drastic reduction in population size, an adaptive life-

445 history strategy when the population is at risk of extinction.

446 For many animal species that frequently experience the often-catastrophic effects of

447 extreme climate or point events - and have limited movement range for physiological and

448 behavioral reasons or for the environment they inhabit (e.g., freshwater fish in mountain

449 streams, insects) - offspring production is typically very high compared to the habitat

450 carrying capacity. Thus, offspring production is not usually what is limiting population

451 recovery, i.e. the re-establishment of the pre-event population size. However, when after

452 a climate or point extreme event the population is reduced to such low numbers that the

453 population is at immediate risk of extinction, younger age at first reproduction for the

454 surviving individuals could be the life-history trait that makes the difference between 
455 population persistence or extinction. Vincenzi et al. (2017) found that fish born after flash

456 floods had younger mean age at reproduction than fish born before flash floods; they

457 hypothesized that younger age at reproduction after flash floods was due to a

458 combination of faster growth due to lower population density and fewer older fish

459 competing for mates. However, younger age at sexual maturity and higher energetic

460 investment in offspring production often come at the cost of shorter life expectancy (Fay

461 et al. 2016), and life histories that are adaptive after population crashes can show lower

462 fitness in steady-state conditions (Vincenzi et al. 2012, 2014).

\section{$463 \quad 4.2$ Prediction of genetic dynamics and of population extinction}

464 Populations experiencing recurrent bottlenecks are expected to have their genetic pool

465 eroded over time. The erosion of the genetic pool should be noticeable in particular in the

466 loss of allelic richness, even after a single bottleneck event (Allendorf 1986). I found that

467 the extent of population bottlenecks, which I operationalized as the number of years in

468 which population size was relatively small with respect to the habitat carrying capacity

469 and species numerical potential, was a strong predictor of allelic richness for the

470 quantitative trait under selection in the simulations. These results appear to be partially

471 consistent with recent empirical results. Vincenzi et al. (2017) found an increase in the

472 proportion of fixed alleles in year-classes of two trout populations born after flash floods

473 that caused massive mortalities. Poff et al. (2018) tested predictions about population

474 genomic change in aquatic insects living in Colorado, US, mountain streams after a 1-in-

475 500-year rainfall event. They found that allelic richness at presumably neutral loci

476 declined after the event only in two out of six species analyzed. Moderate reduction of

477 allelic diversity after strong bottlenecks might be attributable to the particular 
478 demographic history of the populations that are investigated; according to Bouzat

479 (2010), one can expect that populations experiencing recurrent bottlenecks might have

480 had their genetic pool already eroded over time, which would decrease the effectiveness

481 of both purifying selection and random allele loss. In addition, the loss of alleles could be

482 greater in species_like salmonids_—with high variance in reproductive success among

483 adults (i.e., greater than Poisson variance in reproductive success), although high

484 variance in reproductive success has been found to bias (i.e., make false positives more

485 likely) empirical investigations of genetic bottlenecks (Hoban et al. 2013). Moreover, in

486 the simulations of population dynamics, we started from 10 unique alleles for each of the

48710 loci, and the high initial allelic diversity may explain the strong relationship that was

488 found between the temporal extent of bottlenecks and allelic richness.

489 On the other hand, a model including age at first reproduction and fecundity of the

490 species, along with some traits of the environment, was not able to predict the dynamics

491 of the population frequencies of more advantageous alleles for the quantitative trait under

492 selection. However, a strong correlation was found between the frequencies of more or

493 less advantageous alleles at the end of simulation time and the average value of the

494 phenotype under selection. This result seems to at least suggest that, although the fate of

495 alleles is difficult to predict from just the coarse-grain description of the environment and

496 of the species, even in an extreme environment that also causes trait-independent mass

497 mortalities, a shift in the phenotype is likely to be caused by the increased prevalence of

498 the most advantageous alleles.

499 One of the foundational tenets of conservation biology is that small, fragmented

500 populations should be considered locally vulnerable to extinction-even more critically 
501 so when affected by highly variable climatic conditions and other environmental

502 disturbances. The conditions that led to the extinction of a population or species can

503 almost always be understood retrospectively, but forecasting extinction, especially over

504 contemporary time horizons, is much more challenging. In this work, I found that the

505 most important predictors of contemporary extinctions were mean and minimum

506 population size measured in the few years before the "prediction window". However, it

507 was not uncommon for the simulated populations to swiftly rebound after collapses in

508 numbers, and age at reproduction and yearly fecundity were the most important

509 predictors of extinction when measures of population size were not included in the model.

510 This result highlights the importance of age at first reproduction and yearly fecundity for

511 population persistence in highly stochastic environments, as also suggested by theoretical

512 (Bürger and Lynch 1995) and experimental (Griffen and Drake 2008) studies. However,

513 other genetic challenges not accounted for in my simulation model are likely to be

514 encountered by populations that decline to very small numbers, such as a reduction of

515 viability and/or fecundity due to either inbreeding or the expression of deleterious alleles

516 (Willi et al. 2006).

517 Although it may appear from the simulation results that vital rates and environmental

518 conditions play a small role in models that predict contemporary risk of extinction, those

519 rates and conditions heavily contribute to determining population size in the "observation

520 window"; for example, populations with higher fecundity and younger age at first

521 reproduction are less likely to remain at low population sizes than populations with lower

522 fecundity and delayed sexual maturity. Likewise, a more extreme environment (e.g.,

523 greater selection strength and more frequent and/or severe climate and point extremes) 
524 tends to decrease average population size, either due to acute events that kill individuals

525 or constant recovery from population crashes.

526 Luck also plays a major role in determining whether a population will recover after a

527 population crash. Vincenzi et al. (2017) found that the almost-complete recovery of a

528 trout population that was reduced to a handful of individuals after a flash flood was due

529 to the large production of offspring by a single mating pair. Considering the high

530 variance in adult reproductive success in trout populations - which is at least partially due

531 to differences in individual "quality" (Auld et al. 2019) — had the mating pair been killed

532 or displaced during the flash flood, population recovery would have suddenly become

533 much less likely.

\section{$534 \quad 4.3$ Modeling considerations}

535 Modeling and simulation approaches can help understand the effects of multiple

536 extreme stressors on the contemporary risk of extinction of species and can be used to

537 guide or support both the set-up of ecologically relevant experimental designs and the

538 interpretation of biological responses to multiple stressors.

539 However, models of population and genetic dynamics are limited in their scope of

540 prediction by both the understanding of the biology and ecology of the species and the

541 availability of data to parametrize, train, and test models, along with modeling choices

542 (e.g., explicit or implicit modeling of alleles, clustered or "well-mixed" individuals or

543 populations). Although often intuitive, it is nevertheless important to remind ourselves

544 that the simulation results of modeling exercises depend on, first, our biological and

545 ecological understanding, and, second, the simplified modeling of the species and the

546 environment they inhabit. For instance, general trade-offs between allocation of resources 
547 to competing physiological functions are not only often intrinsically challenging to

548 model, but they may also vary over time and space for the same species or population.

549 That is, even when there is a qualitative understanding of biological or ecological

550 processes, the parameterization and choice of parameter values for the model may be too

551 uncertain to provide actionable predictions.

552 Trade-offs between model accuracy and interpretability also need to be taken into

553 account when developing models of population and genetic dynamics. Accuracy

554 describes the ability of a model to explain observed data and make correct predictions,

555 while interpretability concerns to what degree the model allows for understanding

556 processes. Often, there is a trade-off between accuracy and interpretability: more

557 complex models are usually opaque, while more interpretable models often do not

558 provide the same accuracy or predictive power of more complex models (Breiman

559 2001b). Then, although intuitively more complex models are expected to provide more

560 accurate predictions of risk of extinction or population and genetic dynamics, this is not

561 always the case. For instance, Ward et al. (2014) tested the predictive performance of

562 short-term forecasting models of population abundance of varying complexity. They

563 found that more complex models often performed worse than simpler models, which

564 simply treated the most recent observation as the forecast. In their case, the estimation of

565 even a small number of parameters imposed a high cost while providing little benefit for

566 short-term forecasting of population abundance. However, when there was a clear signal

567 of cyclic dynamics, more complex models were able to more accurately predict future

568 population sizes. 
bioRxiv preprint doi: https://doi.org/10.1101/2020.09.15.298919; this version posted November 26, 2020. The copyright holder for this preprint (which was not certified by peer review) is the author/funder, who has granted bioRxiv a license to display the preprint in perpetuity. It is made available under aCC-BY 4.0 International license.

569 As always, the purpose of a scientific investigation should drive model formulation,

570 the type and amount of data collected, and the acceptable uncertainty of model

571 predictions.

572 


\section{Ethics}

574 Not applicable

575 Data accessibility

576 Data and relevant code for this research work are stored in GitHub:

577 https://github.com/simonevincenzi/Contemporary_Extinction

578 Authors' Contributions

579 Simone Vincenzi conceived the ideas, designed the methods, run the analyses, and

580 wrote the manuscript.

581 Competing interests

582 The author declares no competing interests

\section{$583 \quad$ Funding}

$584 \quad$ Not applicable

\section{Acknowledgements}

586 Simone Vincenzi developed the idea behind this work while walking the Malecón of

587 La Habana, Cuba, and finished writing the manuscript after the 2020 California fires that

588 imperiled the town where he resides (Santa Cruz, CA, US) and the COVID-19 pandemic

589 highlighted the importance of proper simulation modeling for basic science and policy,

590 and the increasing threat of extreme events for people and nature. 


\section{References}

593 Allendorf, F. W. 1986. Genetic drift and the loss of alleles versus heterozygosity. - Zoo

$594 \quad$ Biol. 5: 181-190.

595 Auld, H. L. et al. 2019. Advancing mate choice studies in salmonids. - Rev. Fish Biol.

$596 \quad$ Fish. 29: 249-276.

597 Bailey, L. D. and van de Pol, M. 2016. Tackling extremes: Challenges for ecological and 598 evolutionary research on extreme climatic events. - J. Anim. Ecol. 85: 85-96.

599 Bell, G. and Gonzalez, A. 2009. Evolutionary rescue can prevent extinction following $600 \quad$ environmental change. - Ecol. Lett. 12: 942-8.

601 Bouzat, J. L. 2010. Conservation genetics of population bottlenecks: The role of chance, 602 selection, and history. - Conserv. Genet. 11: 463-478.

603 Breiman, L. 2001a. Random Forests. - Mach. Learn. 45: 5-32.

604 Breiman, L. 2001b. Statistical modeling: The two cultures. - Stat. Sci. 16: 199-231.

605 Brown, J. H. and Kodric-Brown, A. 1977. Turnover rates in insular biogeography: effect

606 of Immigration on extinction. - Ecology 58: 445-449.

607 Bryant, E. H. and Meffert, L. M. 1995. An analysis of selectional response in relation to a 608 population bottleneck. - Evolution. 49: 626.

609 Bürger, R. and Lynch, M. 1995. Evolution and extinction in a changing environment: a

610 quantitative-genetic analysis. - Evolution. 49: 151-163.

611 Carlson, S. M. et al. 2014. Evolutionary rescue in a changing world. - Trends Ecol. Evol. $612 \quad 29: 521-530$.

613 Endler, J. A. 1986. Natural Selection in the Wild. - Princeton University Press.

614 Falconer, D. S. and Mackay, T. F. C. 1996. Introduction to Quantitative Genetics. - 
615 Prentice Hall.

616 Fay, R. et al. 2016. Variation in the age of first reproduction: different strategies or

$617 \quad$ individual quality? - Ecology 97: 1842-1851.

618 Frankham, R. et al. 2014. Genetics in conservation management: Revised

619 recommendations for the 50/500 rules, Red List criteria and population viability

620 analyses. - Biol. Conserv. 170: 56-63.

621 Griffen, B. D. and Drake, J. M. 2008. A review of extinction in experimental populations.

$622 \quad-$ J. Anim. Ecol. 77: 1274-87.

623 Gutschick, V. P. and BassiriRad, H. 2010. Biological extreme events: a research

624 framework. - Eos. 91: 85-91.

625 Hoban, S. M. et al. 2013. High variance in reproductive success generates a false

626 signature of a genetic bottleneck in populations of constant size: A simulation study.

$627 \quad-$ BMC Bioinformatics 14: 309.

628 IPCC 2007. Climate Change 2007. Synthesis Report. Contribution of Working Groups I,

629 II \& III to the Fourth Assessment Report of the Intergovernmental Panel on Climate

$630 \quad$ Change.

631 IPCC 2012. Summary for policymakers. - In: Field, C. B. et al. (eds), Managing the Risks

632 of Extreme Events and Disasters to Advance Climate Change Adaptation.

633 Cambridge University Press, pp. 1-19.

634 Janža, M. 2013. Impact assessment of projected climate change on the hydrological

635 regime in the SE Alps, Upper Soča River basin, Slovenia. - Nat. Hazards 67: 1025-

6361043.

637 Jentsch, A. et al. 2007. A new generation of climate change experiments: events, not 
638 trends. - Front. Ecol. Environ. 6: 315-324.

639 Kingsolver, J. G. et al. 2001. The strength of phenotypic selection in natural populations.

$640 \quad$ - Am. Nat. 157: 245-61.

641 Kirkpatrick, M. and Jarne, P. 2000. The effects of a bottleneck on inbreeding depression 642 and the genetic load. - Am. Nat. 155: 154-167.

643 Lande, R. 1995. Mutation and conservation. - Conserv. Biol. 9: 782-791.

644 Lynch, M. and Walsh, B. 1998. Genetic and analysis of quantitative traits. - Sinauer.

645 Lytle, D. A. 2000. Biotic and abiotic effects of flash flooding in a montane desert stream.

646 - Arch. fur Hydrobiol. 150: 85-100.

647 Lytle, D. A. and Poff, N. L. 2004. Adaptation to natural flow regimes. - Trends Ecol.

648 Evol. 19: 94-100.

649 Mangel, M. and Tier, C. 1993. A simple direct method for finding persistence times of

650 populations and application to conservation problems. - Proc. Natl. Acad. Sci. U. S.

$651 \quad$ A. $90: 1083-1086$.

652 McCullagh, P. and Nelder, J. A. 1989. Generalized Linear Models. - Chapman \& $653 \quad$ Hall/CRC.

654 Poff, N. L. R. et al. 2018. Extreme streams: species persistence and genomic change in 655 montane insect populations across a flooding gradient. - Ecol. Lett. 21: 525-535.

656 Reznick, D. et al. 2002. r- and K-selection revisited: The role of population regulation in 657 life-history evolution. - Ecology 83: 1509.

658 Schielzeth, H. 2010. Simple means to improve the interpretability of regression 659 coefficients. - Methods Ecol. Evol. 1: 103-113.

660 The One Earth Editorial Team. 2020. Shocks to the System. - One Earth 2: 487-488. 
661 van de Pol, M. et al. 2017. Behavioural, ecological and evolutionary responses to extreme

662 climatic events: challenges and directions. - Philos. Trans. R. Soc. B Biol. Sci. 372:

66320160134.

664 Vincenzi, S. 2014. Extinction risk and eco-evolutionary dynamics in a variable

665 environment with increasing frequency of extreme events. - J. R. Soc. Interface 11:

66620140441.

667 Vincenzi, S. et al. 2012. Selective consequences of catastrophes for growth rates in a

668 stream-dwelling salmonid. - Oecologia 168: 393-404.

669 Vincenzi, S. et al. 2014. Eco-evolutionary dynamics induced by massive mortality events.

$670 \quad-$ J. Fish Biol. 85: 8-30.

671 Vincenzi, S. et al. 2016. Within and among-population variation in vital rates and

672 population dynamics in a variable environment. - Ecol. Appl. 26: 2086-2102.

673 Vincenzi, S. et al. 2017. Genetic and life-history consequences of extreme climate events.

674 - Proc. R. Soc. B Biol. Sci. 284: 20162118.

675 Ward, E. J. et al. 2014. Complexity is costly: a meta-analysis of parametric and non-

676 parametric methods for short-term population forecasting. - Oikos 123: 652-661.

677 White, E. R. 2019. Minimum time required to detect population trends: the need for long-

678 term monitoring programs. - Bioscience 69: 26-39.

679 Willi, Y. and Hoffmann, A. A. 2009. Demographic factors and genetic variation

680 influence population persistence under environmental change. - J. Evol. Biol. 22:

$681 \quad 124-33$.

682 Willi, Y. et al. 2006. Limits to the adaptive potential of small populations. - Annu. Rev.

$683 \quad$ Ecol. Evol. Syst. 37: 433-458. 
684 Winemiller, K. O. 2005. Life history strategies, population regulation, and implications

685 for fisheries management. - Can. J. Fish. Aquat. Sci. 885: 872-885.

686 Wood, S. 2006. Generalized additive models: an introduction with R. - Chapman \& Hall.

687 Zhang, X. 2012. Fisher' s geometrical model of fitness landscape and variance in fitness.

688 - Evolution. 66: 2350-68.

689

690 


\section{Tables}

692

693 Table 1. Values of parameters of the model of population and genetic dynamics.

694

\begin{tabular}{|c|c|c|}
\hline Parameters & Values & Description \\
\hline$K$ & 500 & Population ceiling \\
\hline$\lambda_{\mathrm{o}}$ & $1.0,1.5,2.0,2.5$ & $\begin{array}{l}\text { Intensity of the Poisson distribution of } \\
\text { yearly number of offspring per mating } \\
\text { pair }\end{array}$ \\
\hline$a_{\mathrm{f}}$ & $1,2,3,4$ & Age at first reproduction \\
\hline$t_{\mathrm{ch}}$ & 100 & $\begin{array}{l}\text { Years since the start of the simulation } \\
\text { before climate change }\end{array}$ \\
\hline$t_{\text {inc }}$ & 25 & $\begin{array}{l}\text { Time of increase of variability (variance } \\
\text { of the normal distribution of the climate } \\
\text { variable) after climate change }\end{array}$ \\
\hline$n_{1}$ & 10 & Number of diploid loci \\
\hline$\sigma_{A}^{2}$ & $6.2510^{-3}$ & $\begin{array}{l}\text { Additive genetic variance per locus at the } \\
\text { start of simulation }\end{array}$ \\
\hline$\sigma_{\mathrm{a}}^{2}$ & $2.510^{3}$ & $\begin{array}{l}\text { Variance of the normal distribution of } \\
\text { allelic values }\end{array}$ \\
\hline$\sigma_{G}^{2}$ & 0.2 & $\begin{array}{l}\text { Additive genetic variance of the } \\
\text { quantitative trait at the start of simulation }\end{array}$ \\
\hline$\mu_{E}$ & 0 & Mean environmental effect \\
\hline
\end{tabular}




\begin{tabular}{|c|c|c|}
\hline$\sigma_{E}^{2}$ & 1 & Environmental variance \\
\hline$m_{E}$ & $0.3,0.5,07$ & $\begin{array}{l}\text { Mortality caused by the point extreme } \\
\text { event }\end{array}$ \\
\hline$S$ & $8,1110^{-2}$ & Strength of selection \\
\hline $\mathrm{p}\left(E_{\mathrm{b}}\right)$ & $510^{-2}$ & $\begin{array}{l}\text { Probability of occurrence of point } \\
\text { extreme events before climate change }\end{array}$ \\
\hline $\mathrm{p}\left(E_{\mathrm{a}}\right)$ & $5,10,1510^{-2}$ & $\begin{array}{l}\text { Probability of occurrence of point } \\
\text { extreme events after climate change }\end{array}$ \\
\hline$\mu_{\Theta, 0}$ & 0 & $\begin{array}{l}\text { Mean of the normal distribution of the } \\
\text { phenotypic optimum from year } 1 \text { to } t_{\mathrm{ch}}\end{array}$ \\
\hline$\sigma_{\Theta, 0}$ & 1 & $\begin{array}{l}\text { Standard deviation of the normal } \\
\text { distribution of the phenotypic optimum } \\
\text { from year } 1 \text { to } t_{\mathrm{ch}}\end{array}$ \\
\hline$\beta_{\mu, \Theta}$ & $0,1.510^{-2}$ & $\begin{array}{l}\text { Annual increase (directional trend) of the } \\
\text { mean of the normal distribution of the } \\
\text { climate variable from year } t_{\mathrm{ch}} \text { to the end } \\
\text { of simulation }\end{array}$ \\
\hline$\beta_{\sigma, \Theta}$ & $0,1,1.510^{-2}$ & $\begin{array}{l}\text { Annual increase of the standard deviation } \\
\text { of the normal distribution of the climate } \\
\text { variable from year } t_{\mathrm{ch}} \text { to } t_{\mathrm{ch}}+t_{\mathrm{inc}}\end{array}$ \\
\hline
\end{tabular}


697 Table 2. Performance of Ordinary Least-Squares regression models (OLS),

698 Generalized Additive Models (GAM) and Random Forest models (RF) when predicting

699 the total number of alleles at the end of simulation time for the replicates that did not go

700 extinct. All populations started with 10 alleles for each of the 10 loci for a total of 100

701 unique alleles. Full models include as predictors $n \_l o w, \beta_{\sigma, \Theta}, \beta_{\mu, \Theta}, \mathrm{p}\left(E_{\mathrm{a}}\right), m_{E}, a_{\mathrm{f}}$,

$702 \lambda_{\mathrm{o}}$, and $s . n_{\text {llow }}$ is the number of years the population was below 150 individuals and all

703 other symbols are as in Table 1 (results were similar with $t r_{-} l o w=100$ or 50 and are

704 reported in the computer code associated with this paper). The training data set had

70521523 replicates ( $80 \%$ of the replicates that survived up to the end of simulation time)

706 and the test data set had 5371 replicates. $R^{2}$ was calculated with respect to the $1: 1$

707 predicted-observed line; $M A E$ is the mean absolute error calculated over the whole test

708 data set. Over the entire data set (training and test), the number of alleles at the end of

709 simulation time was [mean $\pm \mathrm{sd}] 79.84 \pm 21.11$.

710

711

712

713

714

715

\begin{tabular}{l|l|l} 
Model & $R^{2}$ & $M A E$ \\
\hline RF_full & 0.82 & 6.6 \\
RF_red & 0.24 & 15.0 \\
GAM_full & 0.78 & 7.8 \\
OLS_full & 0.71 & 8.8 \\
OLS_red & 0.22 & 15.2 \\
\hline
\end{tabular}


716 Table 3. Generalized Linear Model with logit link function for prediction of extinction

717 (1)/persistence (0) of a population over a 10-year period (“prediction window”) with

718 predictors minimum population size $\min (N)$, mean population size $\bar{N}$, maximum value of

719 the optimum phenotype $\max (\Theta)$, maximum and minimum mean population-level

720 maladaptation (or "extremeness" of the climate extreme) $\max (\Theta(t)-z(t))$ and

721 mean $(\Theta(t)-z(t))$, and occurrence of a point extreme $E$, all measured in the 10 years before

722 the start of the "prediction window" (i.e., in the "observation window"), along with

723 selection strength $s$, age at first reproduction $a_{\mathrm{f}}$ and expected yearly number of offspring

724 per pair $\lambda_{0}$ (full model). In the reduced model, I excluded $\min (N)$ and $\bar{N}$. All predictors

725 were standardized ( $s$ and $E$ are categorical variables with two levels each and they were

726 not standardized) and I report mean estimate and standard error of the regression

727 coefficients for the GLM models (estimate, standard errors and significance where

728 applicable for the GAM and RF models are in the computer code associated with this

729 paper). The GLM, GAM, and RF models were trained on 39547 replicates (36\% went

730 extinct) and tested on 4600 replicates (50\% went extinct). For the full and reduced GLM

731 models, when using the optimal cutoffs $(f u l l=0.54$, reduced $=0.35)$, accuracy when

732 tested on the validation data set was $97 \%$ for the full model and $77 \%$ for the reduced

733 model, false positive rate 0.03 and 0.26 , false negative rate 0.03 and 0.19 . For the GAM

734 models (details in computer code associated with this article), optimal cutoffs were 0.38

735 for the full model and 0.35 for the reduced model, accuracy $97 \%$ and $77 \%$, false positive

736 rate 0.03 and 0.25 , false negative rate 0.03 and 0.20 . For the RF models, accuracy when

737 tested on the test data set was $97 \%$ for the full model and $72 \%$ for the reduced model,

738 false positive rate 0.02 and 0.16 , false negative rate 0.04 and 0.38 . 
bioRxiv preprint doi: https://doi.org/10.1101/2020.09.15.298919; this version posted November 26, 2020. The copyright holder for this preprint (which was not certified by peer review) is the author/funder, who has granted bioRxiv a license to display the preprint in perpetuity. It is made available under aCC-BY 4.0 International license.

\begin{tabular}{l|c|c} 
& full & reduced \\
& & \\
& & \\
\hline Intercept & & $-2.39(0.03)$ \\
$\min (N)$ & $-5.63(0.14)$ & - \\
$\bar{N}$ & $-5.41(0.20)$ & \\
$S$ & $-1.34(0.10)$ & - \\
$\max (\Theta)$ & $0.62(0.06)$ & $-0.11(0.02)$ \\
$\lambda_{0}$ & $-0.14(0.04)$ & $-0.89(0.01)$ \\
$a_{\mathrm{f}}$ & $-0.42(0.03)$ & $0.80(0.01)$ \\
$E$ & $0.42(0.03)$ & $1.50(0.03)$ \\
$\max (\Theta(t)-z(t))$ & $0.06(0.05)$ & $0.28(0.02)$ \\
$\operatorname{mean}(\Theta(t)-z(t))$ & $0.13(0.04)$ & $0.62(0.03)$ \\
\hline
\end{tabular}




\section{$742 \quad$ Figure captions}

743 Figure 1. Examples of simulation replicates. The black solid line and black points

744 represent population size, circles are point extremes, the gray dashed line is the value of

745 the optimum phenotype $\Theta$, and the solid gray line is the mean phenotype $\bar{z}$ in the

746 population. Both $\Theta$ and $\bar{z}$ are re-scaled for graphical purposes. Parameters for the

747 simulation in panel (a): $\beta_{\sigma, \Theta}=0, \beta_{\mu, \Theta}=1510^{-2}, \mathrm{p}\left(E_{\mathrm{a}}\right)=1010^{-2}, m_{\mathrm{E}}=0.7, a_{\mathrm{f}}=4, \lambda_{0}=2$,

$748 s=1110^{-2} .(\mathrm{b}): \beta_{\sigma, \Theta}=1510^{-2}, \beta_{\mu, \Theta}=1510^{-2}, \mathrm{p}\left(E_{\mathrm{a}}\right)=1510^{-2}, m_{\mathrm{E}}=0.3, a_{\mathrm{f}}=3, \lambda_{0}=2, \mathrm{~s}$

$749=810^{-2} .(\mathrm{c}): \beta_{\sigma, \Theta}=1510^{-2}, \beta_{\mu, \Theta}=0, \mathrm{p}\left(E_{\mathrm{a}}\right)=1510^{-2}, m_{\mathrm{E}}=0.5, a_{\mathrm{f}}=3, \lambda_{0}=1, s=810^{-2}$.

750 In the simulation in panel (c), the population went extinct at year 184. Symbols are as in

751 Table 1.

752 Figure 2. Extinction probability (number of populations going extinct divided by the

753 number of replicates run for a given set of parameter values) for scenarios of: (a)

754 different ages at first reproduction and expected yearly number of offspring per mating

755 pair (solid line: all replicates; dashed line $=$ most extreme environment, i.e., $\mathrm{p}\left(E_{\mathrm{a}}\right)=15$

$\left.75610^{-2}, m\left(E_{\mathrm{a}}\right)=0.7, \beta_{\mu, \Theta}=510^{-2}, \beta_{\sigma, \Theta}=1.510^{-2}\right) ;(\mathrm{b})$ different probability of point

757 extremes and probability of dying from point extremes.

758 Figure 3. Partial non-linear effect of the total number of years in which the population

759 is below 150 individuals during simulation time ( $\left.n \_l o w\right)$ on the total number of alleles at

760 the end of simulation time, as found from the Generalized Additive Model of Table 2.

761 The GAM algorithm found $k=3$ as the optimal number of degrees of freedom for the

762 spline (i.e., a cubic). Model details and results are in the in the computer code associated

763 with this paper. 
764 Figure 4. Panels (a-b): population dynamics of two simulation replicates (details

765 about the replicates are in the computer code associated with this paper). Lines and

766 symbols are as in Figure 1. Panels (c-d) dynamics of allelic frequency for the populations

767 in panels $(a-b)(a \rightarrow c, b \rightarrow d)$. Thin dashed gray lines represent the allelic frequencies

768 measured every 50 years for alleles in the bottom $10 \%$ of allelic values (for (c): $n=10$,

769 allelic value $[$ mean $\pm \mathrm{sd}]=-0.27 \pm 0.08 ;(\mathrm{d}) n=10$, allelic value $=-0.21 \pm 0.04$ ) and thin

770 solid black lines represent the top $10 \%$ (for (c): $n=10$, allelic value $=0.28 \pm 0.08$; (d)

$7710.25 \pm 0.06)$. Thick dashed gray lines represent the average frequency in the population

772 of alleles in the bottom $10 \%$ of allelic values and thick solid black lines represent the

773 average frequency of the top $10 \%$. In (c), the alleles in the bottom $10 \%$ of allelic values

774 were more frequent in the population at the end of simulation time than alleles in the top

$77510 \%$, and vice versa in panel (d).

776 Figure 5. Examples of Generalized Linear Model (GLM), Generalized Additive

777 Model (GAM), and Random Forest (RF) predictions of extinction in a "prediction

778 window" based on climate and population traits observed in a "observation window".

779 Circles are point extremes, the black solid line and black points represent population size,

780 the gray dashed line is the optimum phenotype re-scaled for graphical purposes. The

781 letter O denotes the "observation window" and P the "prediction window". For each

782 model in the legend, 1 means the model predicted extinction (e.g., RF $=1$ means that the

783 RF model predicted extinction) and 0 otherwise; in panel (d), all models predicted

784 extinction, but the replicate did not go extinct. In panel (a) only the RF model predicted

785 extinction and the replicate went extinct, in (b) only the GLM model predicted extinction 
786 and the replicate went extinct, and in (c) only the GAM model predicted extinction and

787 the replicate did not go extinct.

788 Figure 6. Variable importance for the full (panel (a)) and reduced (i.e., without

$789 \min (N)$ and $\bar{N}$, panel (b)) Random Forest models for prediction of extinction in the 10-

790 year "prediction window" based on climate/environmental and population traits measured

791 in the 10-year "observation window". To compute variable importance, for each tree, the

792 prediction accuracy on the out-of-bag portion of the data is recorded, and the same is

793 done after permuting each predictor. The difference between the two accuracies are then

794 averaged over all trees and normalized by the standard error. The most important

795 predictor is assigned the value of 100 and the other predictors are scaled accordingly. 
bioRxiv preprint doi: https://doi.org/10.1101/2020.09.15.298919: this version posted November 26, 2020. The copyright holder for this preprint (which was not certified by peer review) is the author/funder, who has granted bioRxiv a license to display the preprint in perpetuity. It is made available under aCC-BY 4.0 International license.

\section{Figure 1}
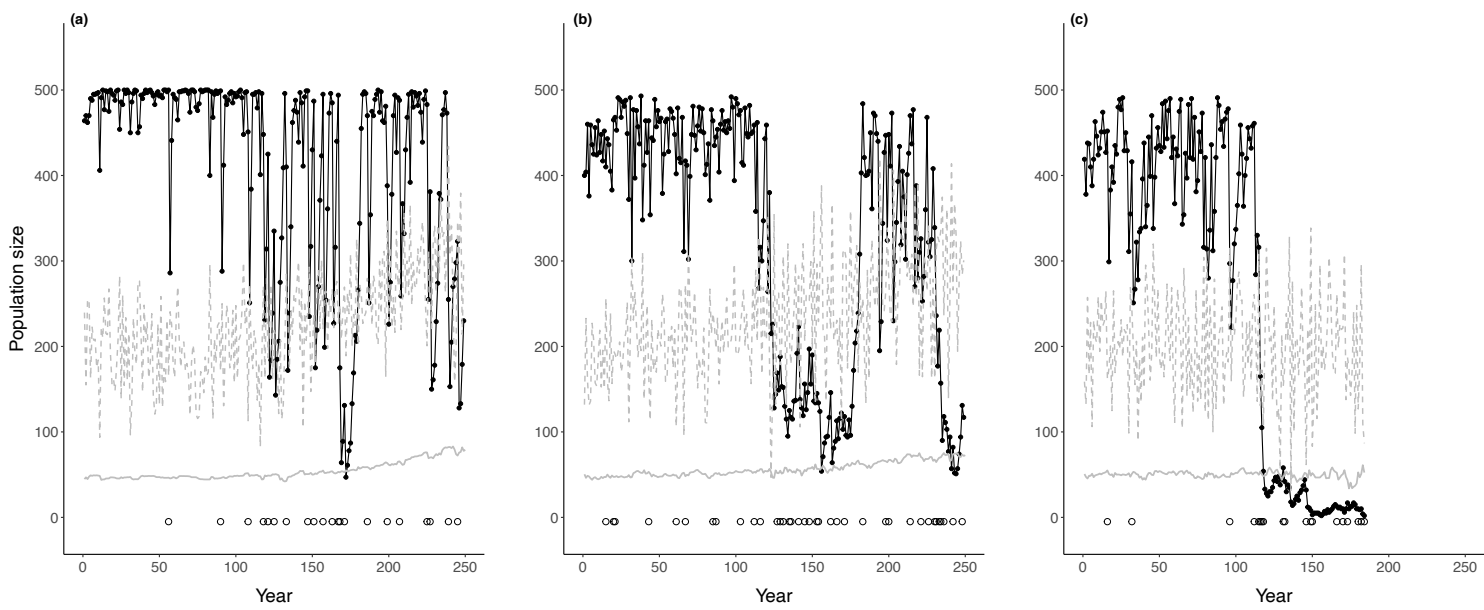
bioRxiv preprint doi: https://doi.org/10.1101/2020.09.15.298919; this version posted November 26, 2020. The copyright holder for this preprint (which was not certified by peer review) is the author/funder, who has granted bioRxiv a license to display the preprint in perpetuity. It is made available under aCC-BY 4.0 International license.

\section{$797 \quad$ Figure 2}
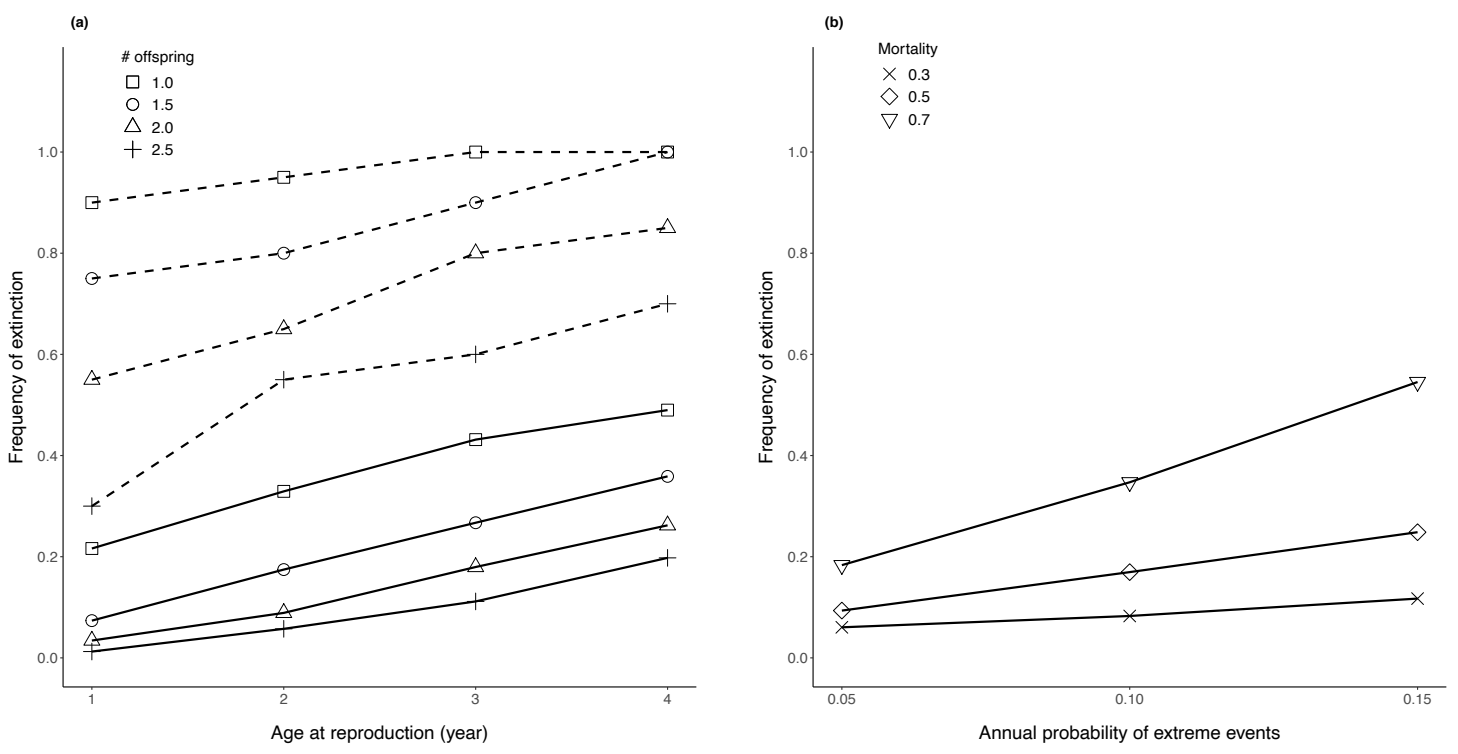
bioRxiv preprint doi: https://doi.org/10.1101/2020.09.15.298919; this version posted November 26, 2020. The copyright holder for this preprint (which was not certified by peer review) is the author/funder, who has granted bioRxiv a license to display the preprint in perpetuity. It is made available under aCC-BY 4.0 International license.

\section{$798 \quad$ Figure 3}

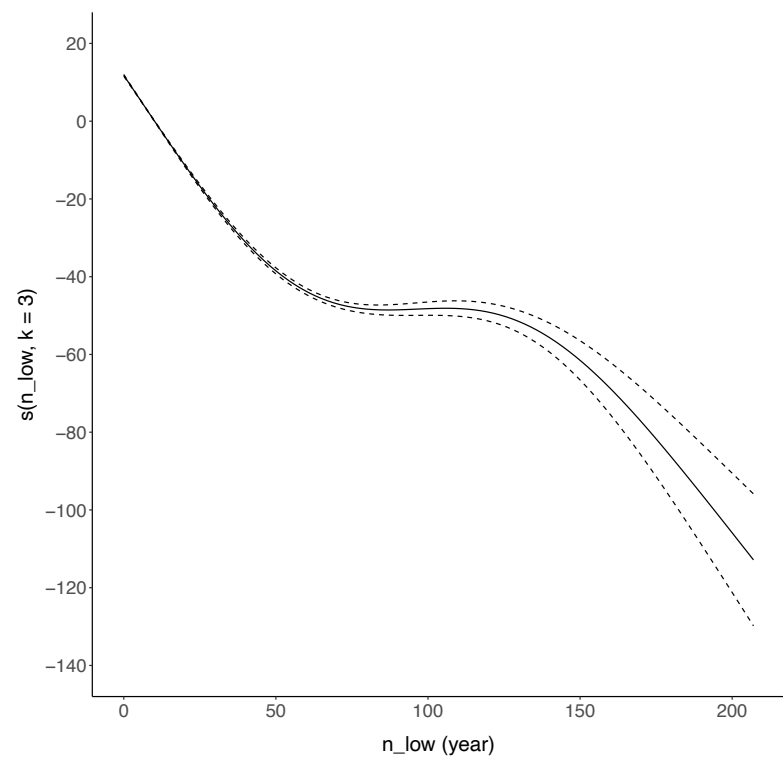


bioRxiv preprint doi: https://doi.org/10.1101/2020.09.15.298919: this version posted November 26, 2020. The copyright holder for this preprint (which was not certified by peer review) is the author/funder, who has granted bioRxiv a license to display the preprint in perpetuity. It is made available under aCC-BY 4.0 International license.

\section{Figure 4}
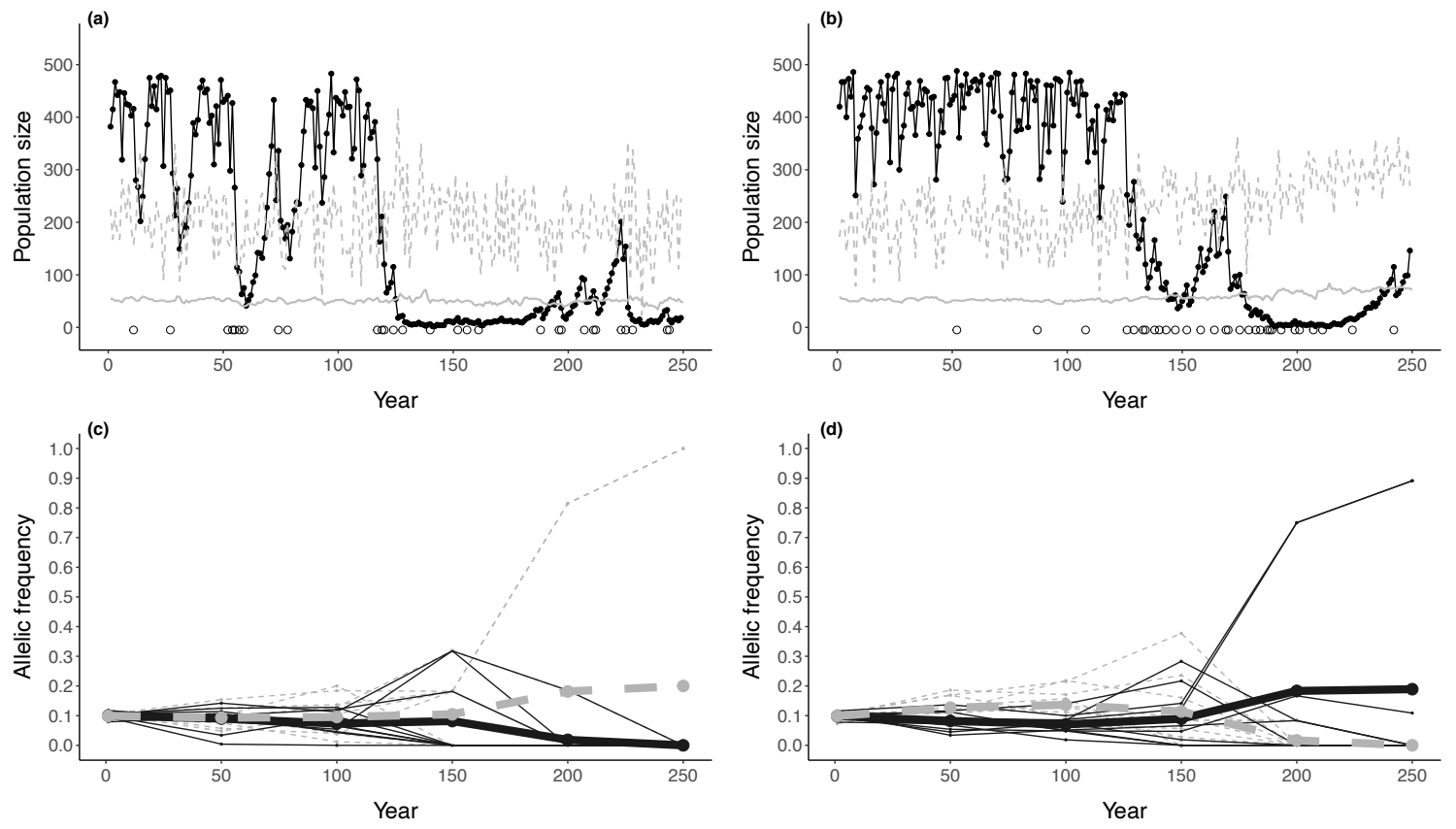
bioRxiv preprint doi: https://doi.org/10.1101/2020.09.15.298919: this version posted November 26, 2020. The copyright holder for this preprint (which was not certified by peer review) is the author/funder, who has granted bioRxiv a license to display the preprint in perpetuity. It is made available under aCC-BY 4.0 International license.

\section{$800 \quad$ Figure 5}
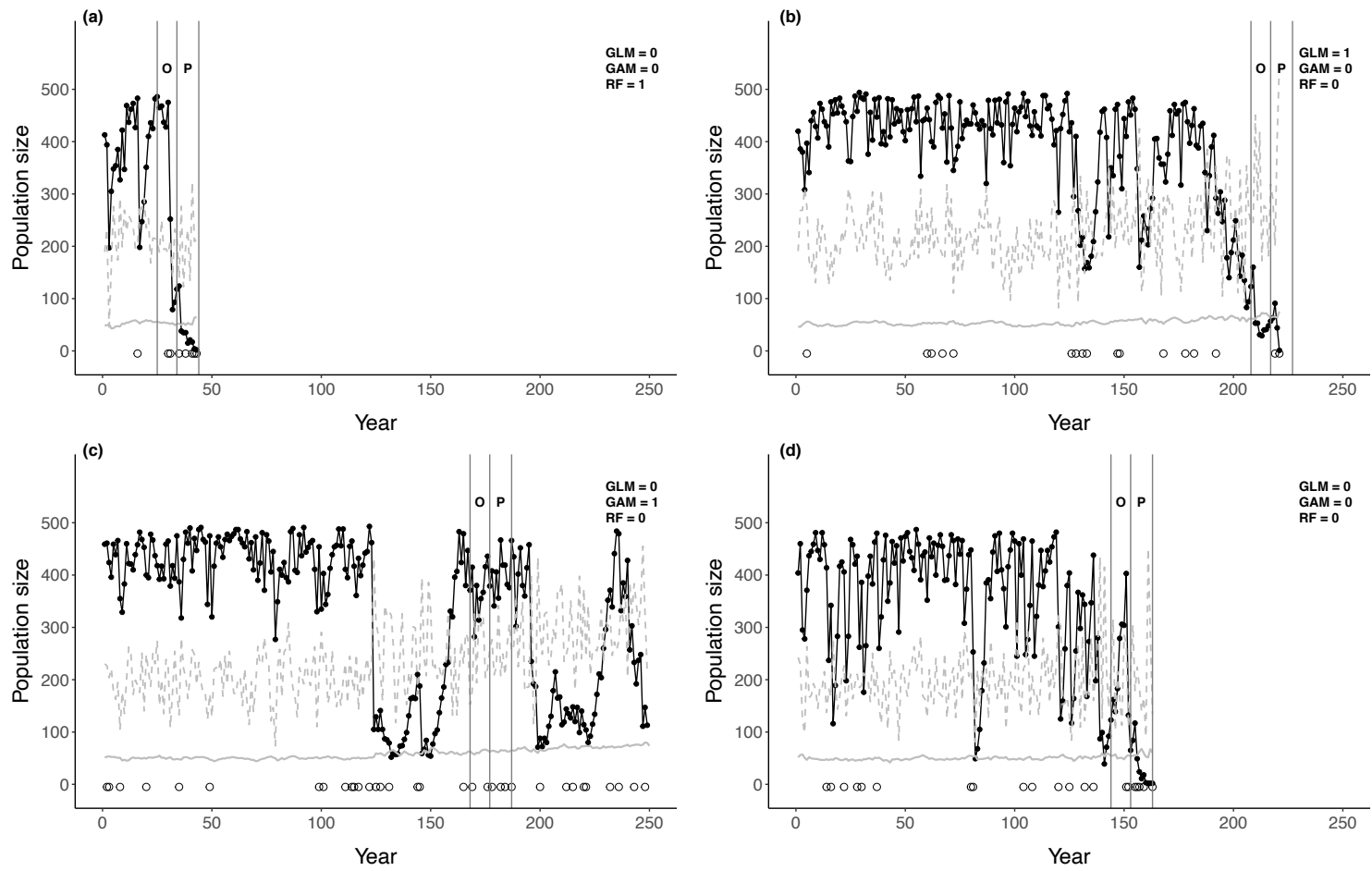
bioRxiv preprint doi: $\mathrm{https}$ //doi.org/10.1101/2020.09.15.298919; this version posted November 26, 2020. The copyright holder for this preprint (which was not certified by peer review) is the author/funder, who has granted bioRxiv a license to display the preprint in perpetuity. It is made available under aCC-BY 4.0 International license.

\section{$801 \quad$ Figure 6}
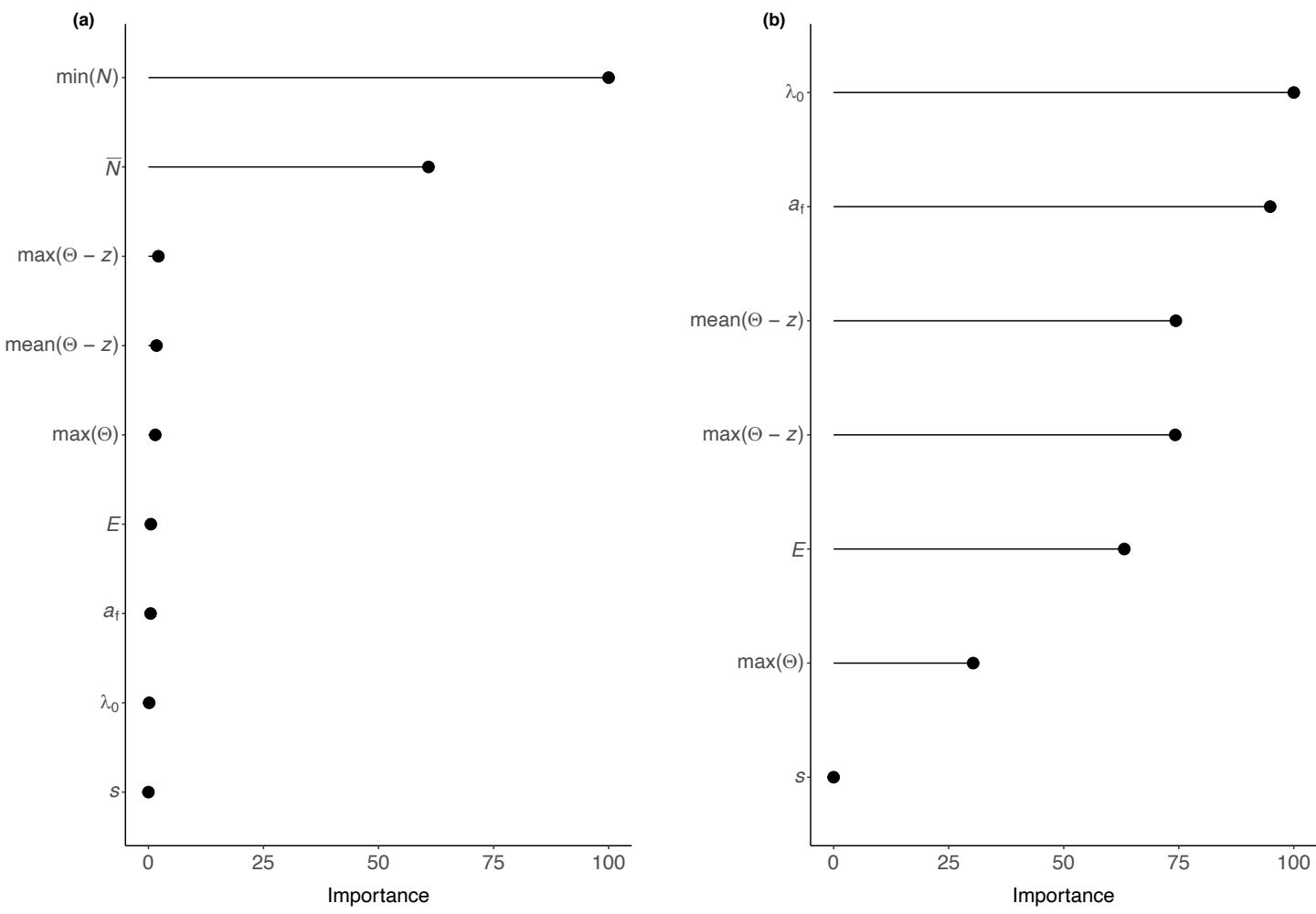